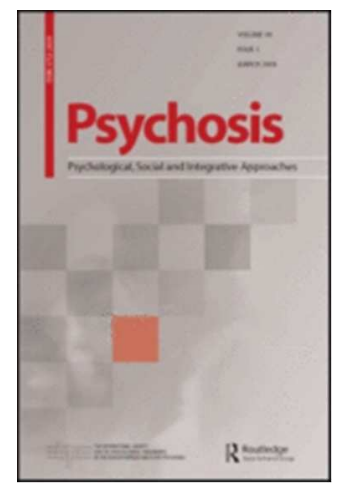

The Dark Side of Being a Clinical Psychologist with Bipolar Disorder: A Response to Ho (2016)

\begin{tabular}{|r|l|}
\hline Journal: & Psychosis \\
\hline Manuscript ID & Draft \\
\hline Manuscript Type: & Letter to the Editor \\
\hline Keywords: & \\
\hline Abstract: & \\
\hline & \\
\end{tabular}

SCHOLARONE ${ }^{\mathrm{m}}$

Manuscripts 


\section{The Dark Side of Being a Clinical Psychologist with Bipolar Disorder: A Response to Ho (2016)}

As a Clinical Psychologist with Bipolar Disorder, I read with great interest the article by Prof. David Y.F. Ho (Ho, 2016) on his experiences of the positive aspects of unipolar mood elevation such as improved memory and increased creativity. Unlike Prof. Ho I have experienced episodes of depression along with hypomania and mania. However what really distinguishes our experiences is these symptoms causing problems. Prof. Ho notes only minor problems associated with these highs, and therefore would not meet the diagnostic criteria for

a Hypomanic or Manic Episode which specify that these much cause impairment in functioning.

I have experienced the pleasurable and productive side of hypomania, with fast working, creative thinking and increased confidence often applied to my academic career. I even became hypomanic about my dissertation on hypomania. However I have also experienced the negative: being hospitalised aged 18 for a manic episode, a hypomanic writing spree of my doctorate thesis being followed by months of depression. I live in constant fear that my ambition, passion and energy for clinical psychology will escalate into a career-destroying manic episode.

I believe that over-emphasising the positive side of hypomania can be problematic. Firstly, it does not do justice to the problems that those with bipolar disorder have and risks hypomania being seen by the wider public as 'fun' rather than potentially destructive. Secondly, if clients focus on the positive effects of their hypomania this can be risky. An important component of a cognitive model of mood swings is that positive appraisals of symptoms (for example "This is the real me, I am great fun") can escalate symptom severity (Mansell, Morrison, Reid, Lowens, \& Tai, 2007). Thus hypomania may escalate into mania 
and more destructive events unfold. The early stage of hypomania is like being on a skateboard going down a steep hill: It's great fun but if you do not get off early it will get faster and faster until you fall off and get hurt.

\section{References}

Ho, D. Y. (2016). Madness May Enrich Your Life: A Self-Study of Unipolar Mood Elevation. Psychosis, 8(2), 180-185.

Mansell, W., Morrison, A. P., Reid, G., Lowens, I., \& Tai, S. (2007). The interpretation of, and responses to, changes in internal states: an integrative cognitive model of mood swings and bipolar disorders. Behavioural and Cognitive Psychotherapy, 35(05), $515-$ 539. 